\title{
PRÁXICAS AFROPERSPECTIVADAS E GRIOTAGENS EM EDUCAÇÃO
}

\author{
Julvan Moreira de Oliveira ${ }^{1}$
}

Jussara Alves da Silva ${ }^{2}$

\begin{abstract}
Resumo: O objetivo desse trabalho foi refletir sobre algumas experiências em formação de professores que abordam as heranças africanas através da oralidade, musicalidade, corporeidade, circularidade, ludicidade, religiosidade, memória e outros valores da cosmovisão africana visando práticas pedagógicas afro-centradas. Tendo base teóricometodológica a "pretagogia" (PETIT, 2015), a "pedagoginga" (ROSA, 2019) e a "pedagogia griô" (PACHECO, 2006), buscou-se analisar a viabilidade dessas experiências na formação docente em relação às questões étnico-raciais na escola. Concluiu-se que as brincadeiras e canções africanas no cotidiano escolar podem ser práticas educacionais com grande potencialidade no sentido da promoção da igualdade racial.
\end{abstract}

Palavras-chave: Africanidades; canções africanas, brincadeiras africanas.

\section{AFRO-PERSPECTIVIZED PRAXIS AND GRIOTAGES IN EDUCATION}

Abstract: The aim of this work was to reflect on some experiences in teacher training that address African heritage through orality, musicality, corporality, circularity, playfulness, religiosity, memory and other values of the African worldview, focusing on Afro-centered pedagogical practices. Based on the theoretical and methodological basis, the "pretagogia" (PETIT, 2015), "pedagoginga" (ROSA, 2019) and "pedagogia griô" (PACHECO, 2006), we tried to analyze the viability of these experiences in teacher training in relation to ethnic-racial issues in the school. It was concluded that African

\footnotetext{
${ }^{1}$ Professor do Programa de Pós-graduação em Educação da Universidade Federal de Juiz de Fora (UFJF); Doutor em Educação pela Universidade de São Paulo (USP); Especialista em Ciências Sociais (Antropologia, Sociologia e Política) pela Fundação Escola de Sociologia e Política de São Paulo (FESPSP); Graduado em Filosofia pela Universidade São Francisco (USF-SP); Líder do ANIME (Grupo de Pesquisas em Africanidades, Imaginário e Educação); Membro da área "Filosofia Africana e Afrodiaspórica" da ABPN. E-mail: julvan.moreira@ufjf.edu.br

${ }^{2}$ Mestra em Educação pela Universidade Federal de Juiz de Fora (UFJF); Especialista em História e Cultura Afro-Brasileira e Africana e Educação para as Relações Étnico-raciais e Graduada em Pedagogia pela UFJF; Supervisora pedagógica e professora regente das séries iniciais do ensino fundamental na rede municipal de Juiz de Fora/MG; Coordenadora técnica do eixo de relações étnico-raciais e gênero da supervisão de atenção à educação na diversidade do departamento de inclusão e atenção ao educando na Secretaria de Educação de Juiz de Fora/MG; Membro do ANIME (Grupo de Pesquisas em Africanidades, Imaginário e Educação). E-mail: tutorajussara@gmail.com
} 
jokes and songs in school everyday can be educational practices with great potential in the sense of promoting racial equality.

Keywords: Africanities; African songs, African play games.

\section{PRAXIS AFROPROPECTIVIZADAS Y GRIOTAJES EN EDUCACIÓN}

Resumen: El objetivo de este trabajo fue reflexionar sobre algunas experiencias en la formación docente que abordan la herencia africana a través de la oralidad, la musicalidad, la corporalidad, la circularidad, la alegría, la religiosidad, la memoria y otros valores de la cosmovisión africana, centrándose en las prácticas pedagógicas afrocentradas. Con base en la base teórica y metodológica, la "pretagogia" (PETIT, 2015), la "pedagoginga" (ROSA, 2019) y la "pedagogia griô" (PACHECO, 2006), intentamos analizar la viabilidad de estas experiencias en la formación del profesorado. Relación con las cuestiones étnico-raciales en la escuela. Se concluyó que las bromas y canciones africanas en la escuela todos los días pueden ser prácticas educativas con un gran potencial en el sentido de promover la igualdad racial.

Palabras clave: Africanidades; Canciones africanas, juegos africanos.

\section{PRAXIS AFROPERSPECTIVES ET GRIOTAGES DANS L'ÉDUCATION}

Résumé: L'objectif de ce travail était de réfléchir à certaines expériences de formation des enseignants qui abordent le patrimoine africain à travers l'oralité, la musicalité, la corporalité, la circularité, le jeu, la religiosité, la mémoire et d'autres valeurs de la vision du monde africaine, en se concentrant sur les pratiques pédagogiques afro-centrées. Sur la base théorique et méthodologique, la «pretagogia» (PETIT, 2015), «pedagoginga» (ROSA, 2019) et «pedagogia griô» (PACHECO, 2006), nous avons tenté d'analyser la viabilité de ces expériences de formation des enseignants en relation avec les problèmes ethniques et raciaux à l'école. Il a été conclu que les blagues et les chansons africaines à l'école tous les jours peuvent être des pratiques éducatives à fort potentiel dans le sens de la promotion de l'égalité raciale.

Mot clé: Les africanités; chansons africaines, jeux africains.

\section{INTRODUÇÃO}

Frente à problemática de uma escola que por questões várias acaba por reproduzir práticas pedagógicas excludentes e preconceituosas, faz-se cada dia mais necessário um trabalho multicultural que contemple as diversas identidades que ali transitam e para tal surgem experiências educativas que buscam descolonizar em alguma medida o ambiente escolar e que carecem de serem analisadas.

A apresentação sistemática das variadas culturas pertencentes às diversas localidades mundiais, sem critérios de hierarquização, partindo do princípio de que todas

Revista da ABPN • v. 12, n. $31 \cdot \operatorname{dez} 2019$ - fev 2020, p. 72-94 
as culturas são imensamente ricas e fascinantes, subsidia algumas práticas que observamos no contexto escolar e de formação, nos mais diversos segmentos educacionais ou não, que já são concretizadas enquanto percurso profissional e que analisaremos nesse trabalho à luz de um referencial teórico-metodológico afroreferenciado. Reconhecemos que:

\begin{abstract}
As ideias pedagógicas estudadas no Brasil têm suas raízes na filosofia ocidental. Nessa perspectiva, outros valores civilizatórios, como os africanos, são excluídos da Pedagogia, assim como da Filosofia, da Psicologia, da Física, da Biologia etc. As culturas africanas são consideradas apenas como do campo da Etnografia e, em alguns casos, da Sociologia e da História. Há um desconhecimento sobre a forma de pensar, sobre a visão de mundo, sobre uma educação fundada na cultura mítico-filosófica africana (OLIVEIRA, 2009, p. 3).
\end{abstract}

Nesse sentido, tendo como base teórico-metodológico a "pretagogia" (PETIT, 2015), a "pedagoginga" (ROSA, 2019) e a "pedagogia griô" (PACHECO, 2006), objetivamos refletir sobre algumas experiências em formação de professores que abordam as heranças africanas através da oralidade, musicalidade, corporeidade, circularidade, ludicidade, religiosidade, memória e outros valores da cosmovisão africana visando práticas pedagógicas afro-centradas.

Inicialmente, levantamos produções acadêmicas que de alguma forma abordam brincadeiras e canções tradicionais e/ou africanas com o intuito de tomarmos ciência do que já vem sendo estudado e visibilizado em relação à temática proposta.

Temos observado mais atentamente a formação de professores de todos os segmentos escolares, deparando-nos com intervenções exitosas que abordam as heranças africanas de maneira alegre e prazerosa através da oralidade, musicalidade, corporeidade, circularidade, ludicidade, religiosidade, memória, ancestralidade, cooperativismo e a energia vital, valores tradicionais africanos.

Em seguida, apresentamos de forma sucinta três pedagogias afro-referenciadas: "Pretagogia", "Pedagoginga" e "Pedagogia Griô", que formaram a base teórica e metodológica, de modo a conseguirmos estabelecer relações entre as práticas e as brincadeiras e canções africanas observadas no trabalho de formação docente de uma professora da Rede Municipal de Ensino de uma cidade do interior de Minas Gerais.

Por fim, abordaremos as brincadeiras e canções africanas aplicadas por uma professora em cursos de formação de professores, de modo a percebermos a viabilidade ou não, e também proporcionarmos o compartilhamento dessas experiências na formação docente em relação às questões étnico-raciais na escola.

Revista da ABPN • v. 12, n. $31 \cdot \operatorname{dez} 2019$ - fev 2020, p. 72-94 
De antemão podemos citar algumas práticas e práxicas cotidianas escolares ou não, em que os elementos e valores tradicionais são perpassados mesmo que de forma não intencional, como nas cirandas, rodas de conversa, jogos cooperativos, leituras de imagens e cantorias.

Segundo Silva (2019, pp. 66-67), “aprendemos e compreendemos o mundo, não somente a partir das palavras escritas ou lidas, mas também e inicialmente o aprendemos através do nosso corpo, nossas vozes, nossas expressões, vivências e experiências individuais ou coletivas".

Esperamos que esse trabalho, além de visibilizar práticas pedagógicas afrocentradas, onde por afrocentrismo consideramos a perspectiva teórica e filosófica do africano reconhecido como sujeito produtor de conhecimento e cultura e não mero objeto de pesquisa, propor o que denominaremos de práxicas afroperspectivadas através de griotagens, pois como assinalam Nascimento e Oliveira (2016, p.190):

A questão da (re)construção identidade negro-africana que rompe com o etnocentrismo está associada ao desligamento com o domínio colonial. O debate sobre a filosofia africana leva-nos a descontruir o processo de colonização da África e as perspectivas dos pensamentos pós-coloniais comprometidos com a preservação das culturas africanas e das identidades diaspóricas, assim como e os requisitos para a identificação dos conhecimentos tradicionais ou endógenos e sua integração nos vários programas educacionais ou programas específicos nas escolas e universidades.

Brincadeiras e canções em línguas africanas disseminarão o sentimento de liberdade e emancipação dos estudantes negros e negras, bem como dos estudantes não negros, através da oralidade, ludicidade, corporeidade e demais valores civilizatórios tradicionais africanos que convergem muito bem com as habilidades e competências educacionais as quais a escola se determina a desenvolver e a potencializar.

\section{BRINCADEIRAS E CANÇÕES AFRICANAS}

Inicialmente pesquisamos os descritores "brincadeiras africanas" e "canções africanas", sem delimitação temporal ou regional, em teses, dissertações e artigos científicos, objetivando verificar as produções acadêmicas sistematizadas existentes em relação a essas temáticas.

Consideramos o vocábulo "africano" nos termos elencados, pela origem continental das brincadeiras e canções e não pela delimitação regional/temporal/cultural

Revista da ABPN • v. 12, n. $31 \cdot \operatorname{dez} 2019$ - fev 2020, p. 72-94 
de grupos étnicos específicos. Porém, em muitas buscas, deparamo-nos com nenhum resultado para os termos "brincadeiras africanas" e "canções africanas" e como alternativa, optamos por iniciar a pesquisa pelas expressões "brincadeiras tradicionais" e "canções tradicionais" considerando como tradicional algo que converge com questões referentes as culturas e costumes orais e memoriais como é a especificidade da cultura africana.

Buscando os termos "brincadeiras africanas" e "canções africanas" não obtivemos resultados, alterando os termos da busca para "brincadeiras tradicionais" obtivemos os trabalhos apresentados abaixo. Antes, porém, importante ressaltar que não compreendemos "africanas" por "tradicionais", compreendendo a particular e a segunda universal. $\mathrm{O}$ foco era saber se haveriam pesquisas sobre brincadeiras tradicionais que falavam sobre as africanas:

- "Ensino de língua espanhola: o uso de brincadeiras tradicionais como recurso para aprendizagem no ensino fundamental”, de Elaine Gomes Viacek Oliani, 2016.

- "Brincadeiras tradicionais da cultura da infância na formação musical do pedagogo", de Monique Traverzim, 2015.

- "Jogos e brincadeiras tradicionais e eletrônicas infantis: significados do brincar para crianças de uma escola pública do município de Piracicaba-SP”, de Benecta Patricia Fernandes e Fernandes, 2015.

- “A cultura lúdica das crianças contemporâneas na 'sociedade multitela': o que revelam as 'vozes' de meninos e meninas de uma instituição de educação infantil", de Marluci Guthia Ferreira, 2014.

- "Práticas lúdicas: linha de transmissão intergeracional da cultura comunitária do assentamento recreio", de Rayane Rocha Almeida, 2015.

- "A reprodução interpretativa do obsceno infantil na cultura de pares", de Cibele Noronha de Carvalho, 2013.

- "Brincadeiras tradicionais em espaços escolares e não escolares: um estudo na perspectiva teórica de Gaston Bachelard”, de Meire Luci Bernardes Silva Machado, 2014.

- "Gestos e vozes de papel: Odete Semedo e a reinvenção de passadas e estórias da tradição oral guineense", de Érica Cristina Bispo, 2005.

- "Vestir poder e poder vestir: O tecido social e a trama cultural nas imagens do traje negro", de Silvia Escorel, 2000.

- "Patrimônio gestual da capoeira carioca", de Samantha Eunice de Miranda Marques Pontes, 2006. 
Observamos nesses trabalhos que brincar nos remete à ludicidade e esta tem sua importância no ensino fundamental onde o reconhecimento das contribuições multiculturais leva à valorização da própria cultura. No brincar as crianças acionam a imaginação que dialoga entre arte, filosofia e educação, principalmente utilizando elementos da natureza criativamente favorecendo a coletividade de uma maneira alegre contribuindo ao processo educacional.

Brougère (2008) aponta que não se nasce sabendo brincar, e, esse aprendizado implica numa constante troca com o outro pois trata-se de um aprendizado social. E partindo dessa premissa, o ambiente escolar pode ser campo fértil para esse aprendizado, visto que, brincando a criança se apropria da realidade atribuindo-lhe novos sentidos e significados. "Ela aprende, justamente, a compreender, dominar, e depois produzir uma situação específica, distinta de outras situações” (BROUGÈRE, 2008, p. 98).

A ludicidade, é importante ressaltar, trata-se de um valor civilizatório tradicional africano, bem como a oralidade, musicalidade, corporeidade, circularidade, religiosidade, memória, ancestralidade, cooperativismo e a energia vital, presentes nas brincadeiras e canções africanas, bem como nas habilidades e competências escolares as quais as práticas pedagógicas se debruçam em potencializar e desenvolver nos estudantes.

Traverzim (2015), parte da premissa que todo homem é um ser brincante, e a partir dos jogos e brincadeiras, mesmo sem uma formação específica, docentes sentem-se mais capazes a trabalhar a educação musical no ensino fundamental, e a musicalidade é essencial nas brincadeiras e canções africanas cuja base estruturante é a cultura oral.

As brincadeiras e canções, antigas ou contemporâneas, presentes no cotidiano escolar ou que pelo menos deveriam se manter presentes nele, são grandes possibilidades de interação e contato com aspectos culturais diversos e consequentemente a ampliação do repertório lúdico/pedagógico das relações estabelecidas na escola propiciarão um maior contato com a diversidade cultural e sua valorização por parte dos estudantes envolvidos em tais procedimentos ou modos de aprender.

As brincadeiras tradicionais não foram substituídas pelos jogos eletrônicos contemporâneos como o senso comum acredita e essa informação revela-nos as múltiplas realidades possíveis do brincar infantil. As relações entre as crianças e as mídias eletrônicas sem perderem a ludicidade do brincar, não deixam de buscar as brincadeiras tradicionais quando estão em espaços de convivência coletiva. 
A apresentação de brincadeiras e canções de culturas variadas no ambiente escolar, possibilita que as crianças/estudantes tenham contato com o multiculturalismo através de vivências e experiências corporais e musicais atrativas e livres sem que o objetivo pedagógico e o desenvolvimento de habilidades e diversas competências desejáveis e estimuladas pela escola, seja descartado.

As crianças “(...) brincam pela brincadeira, brincam para aprender novas brincadeiras e brincam para estar com os amigos" (FERNANDES, 2015, p. 75), e nesse contexto têm experiências coletivas que são essenciais às relações interpessoais bem como nas relações étnico-raciais em contextos escolares ou não escolares.

As peculiaridades da cultura articulam-se com as práticas lúdicas infantis revelando assim a possibilidade de trabalhos pedagógicos consistentes baseados e pautados nas transmissões de saberes intergeracionais e não apenas os conhecimentos escolares sistematizados.

Quando falamos de práticas lúdicas infantis, nos remetemos ao conceito mais plural de infância onde as concepções de criança como criadora do seu próprio sistema simbólico e sua cultura, denotam que as diversas infâncias foram se constituindo historicamente e não se trata de um conceito único e imutável.

Os pouquíssimos trabalhos nessas temáticas nos fazem refletir que as brincadeiras e canções africanas, em contexto escolar, devem nos motivar a debruçarmos e imprimirmos esforços sobre esse tema a ser explorado e apropriado positivamente em meio às diversas práticas pedagógicas e modos de aprender que têm como base a apresentação das diversas culturas e consequentemente o respeito à diversidade e pluralidade cultural.

Ressaltamos que encontramos muitas brincadeiras e canções desenvolvidas em meio escolar ou não, aprendidas através de fontes orais e/ou pesquisas não sistematizadas academicamente que podem ser reproduzidas e/ou adaptadas ao contexto e realidades do cotidiano de nossas escolas, famílias e demais lugares onde a interação e relações interpessoais se desdobrem.

Outras formas de conhecermos as brincadeiras e canções africanas são as conversas com africanos e africanas de diferentes países, que por migração ou mesmo passeio, encontram-se ou residem na cidade em que se desenvolveu este estudo.

Essas conversas possibilitam que ao acessarem as memórias de suas infâncias, os africanos e africanas em diáspora, recordem e relatem como se davam as mais diversas 
brincadeiras e canções que aprenderam com seus pais, mães, avós e avôs, enfim familiares e comunidade, no cotidiano de suas casas, escolas ou demais lugares de interação e relação vivenciados.

\section{PEDAGOGIAS AFRO-CENTRADAS}

Para análises das experiências pedagógicas que utilizam brincadeiras e canções africanas, nós utilizamos por base teórico-metodológica três pedagogias afroreferenciadas, a "Pretagogia" (PETIT, 2015; PETIT, 2016), a "Pedagoginga" (ROSA, 2019; ROSA, 2009) e "Pedagogia griô" (PACHECO, 2006).

A "Pretagogia" como uma proposta de referencial teórico-metodológica surge a partir de várias experiências do Núcleo das Africanidades Cearenses, da Faculdade de Educação da Universidade Federal do Ceará, onde a Professora Sandra Haydée Petit e o Professor Henrique Cunha Jr. elaboraram o curso de especialização em "História e Cultura Afro-Brasileira e Africana" realizado no quilombo em Novo Horizonte. Colocando em prática o que já trabalhavam, direcionaram o curso de modo mais afroreferenciado possível, com a cosmovisão africana como eixo central. Conforme Petit (2015), a "Pretagogia" é uma pedagogia do fazer, da práxis, onde valoriza-se a ancestralidade, tradição oral, corporeidade, religiosidade, território e circularidade como fontes e produtoras de saberes legítimos.

O nome foi sugerido por Geranilde Costa, orientanda de Sandra Haydée Petit, como uma inovação pedagógica que visa empretecer a pedagogia no sentido dos referenciais da cosmovisão africana para dentro de uma pedagogia atualmente eurocentrada e branco-centrada, que referencia-se em autores franceses, alemães, portugueses, ingleses, norte-americanos, russos, que por sua vez influenciam as práticas pedagógicas dos professores e professoras brasileiros.

A autora afirma ser uma pedagogia de pretos feita para pretos, brancos e índios na perspectiva da descolonização dos saberes e da transformação da sala de aula num lugar onde a negritude seja protagonista e sujeito histórico. As múltiplas identidades são valorizadas onde há o reconhecimento das singularidades de cada identidade presente na formação do povo brasileiro.

Nessa metodologia, o corpo todo é fonte de conhecimento não limitando-se à mente e ampliando inclusive para os cinco sentidos. Conforme Petit (2016) podemos 
dançar o conhecimento, cantar o conhecimento, teatralizar o conhecimento bem como escrever o conhecimento:

Levantei 30 temáticas possíveis de identificação das africanidades nas nossas vidas, que não pretendem ser exaustivas das influências africanas na brasilidade, mas que reúnem, a meu ver, um escopo relevante de atravessamentos afro no nosso sistema cultural. Chamei tais elementos de marcadores das africanidades, isto é, marcas daquilo que nos conecta, desde membros da nossa linhagem, práticas religiosas e espirituais, artísticas, de saúde, culinárias, arquiteturas, presentes no cotidiano e na memória familiar e coletiva de todos os brasileiros (PETIT, 2016, p. 667).

Algumas estratégias tomadas na "Pretagogia", por ser necessário que professores e professoras despertem em si próprios o pertencimento racial biológico ou não, apagado historicamente pelo racismo, são atividades como a árvore dos afrosaberes (onde cada cursista exercita sua memória em relação ao pertencimento racial) e os marcadores das africanidades, que são dispositivos pedagógicos que permitem o corpo ser reconhecido enquanto fonte de conhecimento e não somente a escrita convencional academicista ser desenvolvida.

Os professores relacionam-se mais sistematicamente com as africanidades em sua vida, negros ou não, iniciando com atividades como a experiência da árvore dos afrosaberes, reconexão que se você não consegue se conectar com os seus, você se conecta com os outros, e nesse caso os outros são os colonizadores gerando uma fuga do pertencimento racial.

A "Pretagogia" possibilita que o trabalho educativo seja conduzido pelas mais variadas formas de linguagens onde, por exemplo, podemos ser acadêmicos não nos atendo apenas a formas convencionais do ato de lecionar e dos processos avaliativos, mas também aos saberes presentes na tradição oral "repassados em mitos, contos, provérbios e simbologias adinkras (ideogramas tradicionais da cultura acã em Gana)" (PETIT, 2016, p. 662). Da forma convencional as pessoas até aprendem, mas não se apropriam efetivamente e afetivamente dos ensinamentos que podem ser transmitidos nas mais diversas possibilidades e de forma integrada.

Podemos notar isso no modus operandi, tanto do africano como do afrodiaspórico: tratam-se de povos que funcionam pela adaptabilidade, flexibilidade e multiplicidade. A aceitação da diferença é intrínseca à cosmovisão africana porque ela é inclusiva (PETIT, 2016, p. 664). 
Os currículos escolares em grande medida negam aos alunos oportunidades efetivas de reconhecerem sua história, e acabam sem saber quem são nem de onde vem seus antepassados e qual a contribuição desses para a formação da sociedade em que vivem. Levar em consideração os valores de cada um dos mais diversos povos existentes, aproxima os alunos de outras realidades consequentemente estimulando uma cultura de abertura e respeito ao outro e afirmação identitária.

A "Pretagogia" tem como seus princípios: o autorreconhecimento afrodescendente, a tradição oral, a apropriação dos valores das culturas de matriz africana, a circularidade, a religiosidade de matriz africana entrelaçada aos saberes e conhecimentos, o reconhecimento da sacralidade, o corpo como produtor espiritual, produtor de saberes, a noção de território como espaço-tempo socialmente construído, o reconhecimento e entendimento do lugar atribuído ao negro.

Partindo desses princípios será possível uma proposta pedagógica que conecte docentes e discentes à sua africanidade e pertencimento racial biológico ou não visto tratar-se de uma relação de ancestralidade cultural que favorece às tradições orais serem também valorizadas enquanto referenciais legítimos de conhecimentos transversais e principalmente a superação de práticas pedagógicas preconceituosas.

A "Pedagoginga" (2019), desenvolvida por Allan da Rosa, traz-nos a proposta teórico-metodológica que procura romper com metodologias de ensino e aprendizagem tradicionais da educação formal, baseando-se em suas experiências com educação popular em cursos desenvolvidos entre 2009 e 2012, que implementava a história e cultura de matriz africana num movimento de educação popular e autônoma que fortaleceu os aspectos sociais e educativos de seus alunos unindo o simbólico com o estético embasado nas memórias e tradições afro-brasileiras discutindo o racismo presente na escola e considerando a cultura afro-brasileira como possibilidade criativa.

A estrutura mental afro-brasileira é integrativa e não excludente, humanista e não tecnicista, polivalente, visa à unidade dos elementos em sua diversidade e não a sua fragmentação, abre espaço ao inesperado e ao desconhecido que trazem novos arranjos e formas de entrosamento, caules novos desenvolvidos de raízes ancestrais (SILVA, 2017, p.185).

Conforme Rosa (2013) a cultura negra em seu saber iniciático e do transmitir-se pelos mais velhos diferente da abstração de um conceito demonstra que é plenamente uma força viva. Parte de exposição/identificação de imagens e dimensões simbólicas que 
façam aflorar imagens arquetípicas como a luta, a faca, a cor branca, o desafio, a palavra, a cabaça, o alimento, os búzios, as folhas. Criticando teorias que separam a imaginação do pensamento racional.

Hermenêuticas fechadas e sem ar impossibilitam uma compreensão digna e instigante dos símbolos que mapearam, matutaram e suaram a sensibilidade negra de nosso país, e o tanto que esses sentimentos de mundo contribuem, em suas perspectivas filosóficas sobre a relação entre o ser humano e tempo, a ecologia, a economia e a arte, as relações de gênero e as relações entre as pessoas de diferentes faixas etárias e experiências. Para um melhor convívio com o diferente faz-se preciso uma ação compreensiva e uma vontade de se desprender da costumeira visão segregacionista e homogeneizadora, racionalizadora e padronizante (ROSA, 2009, p. 57).

A "Pedagoginga" também condena a burocratização e tecnicidade que acabam por despersonalizar e desvalorizar as memórias simbólicas, o experimental e o encantamento do mundo e do ser. Há necessidade do abandono dos modelos etnocêntricos para a possibilidade de uma compreensão maior das diferenças da multiplicidade de cosmovisões diferenciadas das eurocêntricas.

O protagonismo periférico na educação popular da "Pedagoginga" busca a “contaminação lateral, pela margem" não apenas pela inclusão de práticas de matrizes africanas mas também pela abstração e sensibilidade sensório-corporal que nos permite assim melhor desfrutar do conhecimento (SILVA, 2017, p.186).

A "Pedagoginga" busca equiparar o pensamento abstrato à materialidade das experiências passadas e presentes, além de combater o racismo escolar disseminando uma rede de educação popular além do eventismo, da autoidealização e do espetáculo.

Precisamos e buscamos um método que reconheça como relevante o sujeito na escola, na roça, na praça, no terreiro, no encontro de capoeiristas... Como alguém que surge banhado de memória, de sonhos, de espontaneidade, elementos que podem se constituir como fonte de complexidade, como nascente de "ruídos" que fomentam a desorganização de esquemas férreos em sala de aula, ao mesmo tempo em que os alimenta, salpicando ou reformulando questões, atuando como raízes de rupturas ou como ventos que trazem de volta elementos que haviam passado a secundários, ventos que juntam cores e substâncias no mesmo passeio pelo morro de estudar, que apresentam na varanda do conhecimento casais que não se conheciam, para um namoro duradouro ou para um flerte que muda gestos e pulsações (ROSA, 2019, pp. 135-136).

Os saberes ancestrais, a interdisciplinaridade, a educação das sensibilidades e principalmente o legado cultural africano, são alguns dos princípios da "Pedagoginga" que nascem da necessidade popular e voltam-se para o próprio povo utilizando-se de uma 
linguagem acessível onde as ideias e experiências do autor dialogam com as teorias acadêmicas com fluidez próxima da oralidade, através de conceitos e categorias da cosmovisão afro-brasileira.

A "Pedagogia Griô" (2006) foi desenvolvida por Lílian Pacheco, partindo do conhecimento de si e da ancestralidade, promovendo o encontro entre o universo das culturas tradicionais e o da cultura escolar e acadêmica. Memória ancestral, sensibilidade e subjetividades através dos princípios, práticas e modelos de ação pedagógica que transitam pela tradição escrita, acadêmica, escolar, urbana junto a tradição oral, comunitária, vivencial, periférica e rural. A tradição oral em parceria e não subjugada ou em segundo plano.

Um dos elementos muito fortes é a dinâmica de roda onde se entende o simbolismo da totalidade, a importância do fazer sentido num princípio biocêntrico e um espaço de expressão, pois, temos uma subjetividade, porém o outro também a tem, e há uma experiência muito importante que acontece entre um e outro. A mobilização dos saberes e a construção desses a partir da oralidade, ritualísticas e cirandas também são traços marcantes da "Pedagogia Griô".

Habilitar em metodologias progressistas e comunitárias através de oficinas e vivências em escolas e reuniões pedagógicas também tem sido um meio da "Pedagogia Griô" disseminar sua proposta ressignificando a formação e integrando-a ao currículo e métodos das escolas.

A autora reflete acerca da inclusão no que se refere incluir a uma cultura hegemônica, assimilando-se a esta, e pondera a necessidade de uma cultura contrahegemônica através da transformação social, ou como afirma Machado (2002, p. 138):

Eu me reporto a aspectos da vivência com a comunidade e, mais particularmente, com as crianças. E, refletidamente, me permito afirmar que a motivação propiciada pela influência de elementos da cultura afro-brasileira está na identidade cultural do "povo-de-orixá". Está na identidade de cada pessoa, em particular. Está no sentido da leitura dos diversos elementos do meio (realidade). A motivação encontra-se, finalmente, na "palavra dos mais velhos", fonte de conhecimento singular, herança ancestrálica africana.

A "Pedagogia Griô" tem como elementos centrais a identidade e a ancestralidade integrando mito, corporeidade, ciências e saberes tradicionais nas vivências e nos planejamentos dos professores e professoras de forma criativa quebrando a rotina hegemônica das práticas tradicionalistas impostas pelo sistema de ensino atual.

Revista da ABPN • v. 12, n. $31 \cdot \operatorname{dez} 2019$ - fev 2020, p. 72-94 
Reinventando o personagem do Griô Africano (contadores de histórias, músicos, poetas e genealogistas responsáveis pela transmissão da tradição oral no antigo Império do Mali) a "Pedagogia Griô" convida a comunidade e escola a se pautarem no passado e no futuro, memória reflexiva e vivencial, para que a aprendizagem seja significativa e respeite a sabedoria popular ao lado do conhecimento acadêmico.

Seguindo o modelo de espiral de conhecimento, a identidade de cada pessoa fica ao centro e as tradições e ancestralidade são o fio condutor na integração do currículo tradicional ao científico através das ações de três personagens: o Mestre Griô (pessoa mais velha e com história de vida e tradição reconhecida pela comunidade), o Educador Griô (pessoa que questiona a missão de educar e reinventa o currículo oferecendo vínculos entre a comunidade e escola) e o Griô Aprendiz (pessoa que busca iniciação em alguma tradição e vínculo com algum mestre e comunidade).

\section{GRIOTAGENS}

A reflexão que trazemos é sobre o que a educação tem a oferecer aos nossos estudantes como alternativa às práticas pedagógicas eurocêntricas as quais o currículo escolar ainda se encontra imerso.

Para isso, observamos diversas oficinas e cursos de formação de professores, ofertados por uma professora da Rede Municipal de Ensino de um município do interior de Minas Gerais, denominada por nós de "Kadidja"3.

Para Kadikja, o seu trabalho pedagógico é como uma práxica afroperspectivada desde o momento em que entrelaça conhecimentos pedagógicos acadêmicos sistematizados aos estudos afro-referenciados e também ao seu encantamento às culturas africanas e afrodiaspóricas.

Ela utiliza as brincadeiras e canções africanas como disparadores para reflexões e inflexões acerca da (re)educação para as relações étnico-raciais tanto em ambiente escolar quanto em ambiente de educação não formal através das intervenções e ações que denominamos de griotagens.

\footnotetext{
${ }^{3}$ Kadidja é o nome da mãe de Amadou Hampâté Bâ. Utilizaremos esse nome em homenagem à professora, pois como diz Bâ sobre a sua mãe, "tudo o que somos e tudo o que temos, devemos somente uma vez a nosso pai, mas duas vezes a nossa mãe" (BÂA, A. H. 2003, p. 51).
}

Revista da ABPN • v. 12, n. $31 \cdot \operatorname{dez} 2019$ - fev 2020, p. 72-94 
Analisando essa práxica afroperspectivada à luz dos saberes compartilhados pela "Pretagogia", "Pedagoginga" e "Pedagogia Griô", percebemos a possibilidade de arrebanhar mais profissionais da educação - e não somente eles - a perceberem que nas ações mais simples e pontuais experenciadas na escola e fora dela, (re)conhecemos e (re)escrevemos a nossa história de modo a resistirmos ao racismo institucional e estruturante da sociedade que faz com que nos afastemos de nossas origens numa busca tola e genocida por padrões que renegam o valor da nossa identidade étnico-racial.

Estruturando as práxicas afroperspectivadas de Kadidja a partir dos marcadores das africanidades (PETIT, 2016), podemos metodizar as griotagens, de certa maneira, a fim de sistematizarmos, porém sem a pretensão de classificá-las ou formatá-las, o que seria incoerente com a proposta de uma educação contra-hegemônica e fora de padrões pré-estabelecidos como culturalmente legítimos.

Sendo assim, não podemos deixar de comentar que as griotagens acabam por atravessar diversos marcadores simultaneamente, o que não é de se estranhar, pois podemos compreender tanto com a "Pretagogia" quanto na "Pedagogia Griô" e "Pedagoginga" que somos um todo pluriversal e biocêntrico que portanto não se fragmenta e nossos sentidos e sensações também se atravessam e "são necessariamente simbólicos, ou seja, mediadores entre as diversas dimensões vividas, articulando natureza e cultura, o racional e o intuído, o patente e o latente" (BEZERRA, 2012, p. 40).

Buscando contemplar nossos saberes ancestrais, nas atividades de formação de professores e professoras em relação à educação para as relações étnico-raciais bem como nas griotagens com crianças, jovens, famílias e comunidade, as brincadeiras e canções africanas tem se mostrado uma excelente oportunidade ao contato com as culturas africanas de forma lúdica e atrativa, visto que, todos nós em essência e mesmo que não nos demos conta disso, aprendemos de maneira mais significativa brincando e estabelecendo relações concretas com as informações novas, e com as questões etnoculturais não seria diferente.

a miragem da Pedagoginga é firmar no fortalecimento de um movimento social educativo que conjugue o que é simbólico e o que é pra encher a barriga, o que é estético e político em uma proposta de formação e de autonomia, que se encoraje a pensar vigas e detalhes de nossas memórias, tradições, desejos (ROSA, 2013, p. 25).

Aprendemos também com o corpo, com os movimentos e com tudo à nossa volta e as brincadeiras e canções são atividades potentes para desenvolvermos simultaneamente

Revista da ABPN • v. 12, n. $31 \cdot \operatorname{dez} 2019$ - fev 2020, p. 72-94 
de diversas habilidades e competências escolares ou não, junto à consciência de nossa ancestralidade e o fortalecimento de um auto-conceito positivo em relação a negritude ou afrodescendência, no caso dos participantes não-negros.

Mitos, lendas, o ato de contar, valorização da contação, formas de falar e vocabulário afro como marcadores das africanidades sentidos nas brincadeiras e canções africanas.

Destacamos os elementos que nos remetem à cosmovisão/cosmosensação africanas e à contação de narrativas em línguas tradicionais de diversos povos do berço da humanidade, sem delimitar uma região recorte específicos, pois a intenção é, que, partindo da multiplicidade e diversidade possamos despertar interesse em quaisquer aspectos de acordo com a afinidade de cada participante das formações e griotagens.

São práxicas que após estudar e compreender sua dinâmica, são ressignificadas para contemplar as especificidades tanto em relação ao segmento educacional pertencente aos professores e professoras que estejam participando das formações tanto quanto a faixa etária e públicos envolvidos nos processos de vivências e ensinagens quando compartilhadas as griotagens em ambientes escolares e extra-escolares.

Quando Kadidja conta narrativas africanas, muitas vezes como preâmbulo das griotagens, procura dar ritmo sonoro ao enredo, mesmo não existindo referência musical na história escolhida, e faz isso por acreditar que, quando contamos e cantamos simultaneamente, nos envolvemos mais efetivamente ao momento, acabando também por gerar uma memória afetiva positiva em relação ao que foi vivenciado pelo grupo.

As práxicas afroperspectivadas realizadas nos encontros de formação de professores e professoras em relação às questões étnico-raciais (ou nas griotagens junto às crianças, jovens ou comunidade), com brincadeiras e canções africanas em línguas tradicionais, têm possibilitado uma imersão imediata na seara das africanidades e principalmente na desmistificação de que esse trabalho não é possível de ser efetivado nas escolas independente do segmento. Não apenas iniciar, mas fazer com que os encontros sejam atravessados pela musicalidade, corporalidade e ludicidade têm sido extremamente significativos.

As brincadeiras e canções abaixo descritas são uma amostra das inúmeras possibilidades que Kadidja utiliza durante as griotagens e denotam bem o sentimento positivo e esperançoso ao adentrar mais um grupo para semeadura de nossas pautas e questões que nos são tão caras, através do encantamento e musicalização. 


\author{
Funga Alafiá (Yorubá) \\ Funga alafiá \\ Axé, axé \\ Funga alafiá \\ Axé, axé
}

Esta é uma música de recepção e acolhimento das pessoas, utilizada por Kadidja no início de suas atividades, que pode ser compreendida como: "Em ti eu penso, contigo eu falo, gosto de ti, somos amigos!"' (SOUZA, 2017, p. 04).

Com essa canção Kadidja explora o significado da palavra Axé (Asè em yorubá), junção das palavras Awá (nós) / Sé (Realizar), sacralizada como o poder de fazer, realizar e gerar mudanças.

Outra canção utilizada por ela em seus cursos de formação é a "Ayo Ayo". Tratase de um jogo de palavras que pelas imagens chama às crianças a cantarem e dançarem tocando tambores juntas, movimentando várias partes do corpo e batendo as mãos ao ritmo das rimas.
Ayo Ayo (Yorubá)
Dja massé dja
Essé éssé ougna
Ako kissélé
Edo kélédjé
Eh ina baikko
Eh djéssigna kognan
Elé zokoko
Kokoka koloubé
Koloubé kognan
Egnan lokoto
Lokoto lécongo
Aloussa kao kao
Ayo ayo

Analisamos essa canção como uma representação da intimidade, perseveração e pela presença novamente da criança.

A música "Viens Manger", utilizada por Kadidja em algumas de suas oficinas, já é uma representação das imagens da intimidade e afetividade, representado pelo convite a comer e presenças da mãe, da criança e do alimento.

\footnotetext{
Viens Manger (Lingala/Congo e Francês)

Yaka ko lia / Venha comer

Yaka ko lia éh / Venha comer

Yaka ko lia / Venha comer

Yaka ko lia éh / Venha comer
}

Revista da ABPN • v. 12, n. $31 \cdot \operatorname{dez} 2019$ - fev 2020, p. 72-94 
Na simbi libumu / Eu esfrego minha barriga na béti maboko / Eu esfrego minhas mãos Na simbi libumu / Eu esfrego minha barriga na béti maboko / Eu esfrego minhas mãos Na tondi yé é / Eu comi bem sim Na tondi yé / Eu comi bem $\mathrm{Na}$ simbi libumu / Eu esfrego minha barriga na béti maboko / Eu esfrego minhas mãos Na simbi libumu / Eu esfrego minha barriga na béti maboko / Eu esfrego minhas mãos na tondi yé mama / Eu comi bem mamãe na tondi yé / Eu comi bem Viens manger / Vem comer Viens viens viens manger / Vem vem vem comer Viens manger / Vem comer Viens viens manger / Vem vem vem comer Je frotte mon ventre / Eu esfrego minha barriga Je frotte mes mains / Eu esfrego minhas mãos Je frotte mon ventre / Eu esfrego minha barriga Je frotte mes mains / Eu esfrego minhas mãos J'ai bien mangé / Eu comi bem $\mathrm{J}$ 'ai bien mangé oui / Eu comi bem sim Je frotte mon ventre / Eu esfrego minha barriga Je frotte mes mains / Eu esfrego minhas mãos Je frotte mon ventre / Eu esfrego minha barriga Je frotte mes mains / Eu esfrego minhas mãos J'ai bien mangé oui / Eu comi bem sim $\mathrm{J}$ 'ai bien mangé / Eu comi bem

A brincadeira "Ram Ram", em árabe marroquino é um jogo de movimentação corporal que remete às amizades e ao companheiro que dava segurança às viagens, o Rafiq. A instrução é que na expressão "a ram sam sam” batem-se as palmas das mãos nos joelhos, na expressão "guli guli" gire-se as mãos uma sobre a outra num movimento circular, e na expressão “oh Rafiq" mantenham-se as mãos separadas como se estivesse soltando algo pegajoso ou ainda se faça um gesto unindo as mãos e levando-as abaixo da lateral da face como se estivesse dormindo. Nessa parte, Kadidja substitui os gestos por um abraço ao colega de algum dos lados, criando e estreitando os laços afetivos do grupo.

A ram sam sam (Árabe Marroquino)

A ram sam sam, a ram sam sam / A ram sam sam, A ram sam sam guli guli guli guli guli / diga-me, diga-me, diga-me, diga-me, diga-me, ram sam sam / ram sam sam

A ram sam sam, A ram sam sam guli guli guli guli guli ram sam sam / ram sam sam Oh Rafiq, oh Rafiq / Amigo, amigo guli guli guli guli guli / diga-me, diga-me, diga-me, diga-me, diga-me ram sam sam / ram sam sam Oh Rafiq, oh Rafiq / Amigo, amigo 
guli guli guli guli guli / diga-me, diga-me, diga-me, diga-me, diga-me ram sam sam / ram sam sam

Na canção "Pililili" as crianças são chamadas a perseguir os pássaros e caçá-los todas juntas.

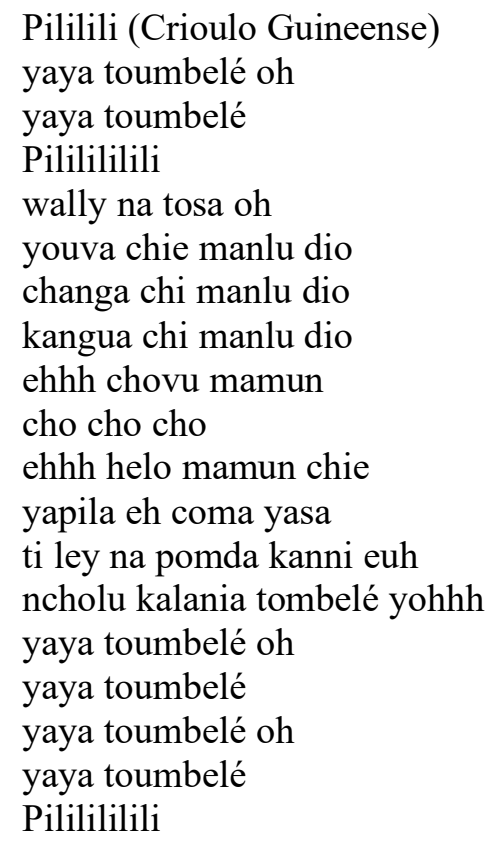

Essa canção tem toda uma representação das imagens de união dos contrários, apesar da presença da perseguição e caça que nos remetem à uma atitude heroica, de caçador. A música no contexto da brincadeira, pelo atributo da intimidade e pelas presenças das crianças caçando galinhas d'angola provavelmente para se alimentar, remete-se a um sacrifício, a uma dimensão sagrada.

As mesmas representações simbólicas parecem estar na música "Ngano ya Tsuro na Gudo". A presença da caça aparece, porém com muito mais ênfase na intimidade da relação de amizade entre os personagens e nos gestos do alimento obtido e partilhado.

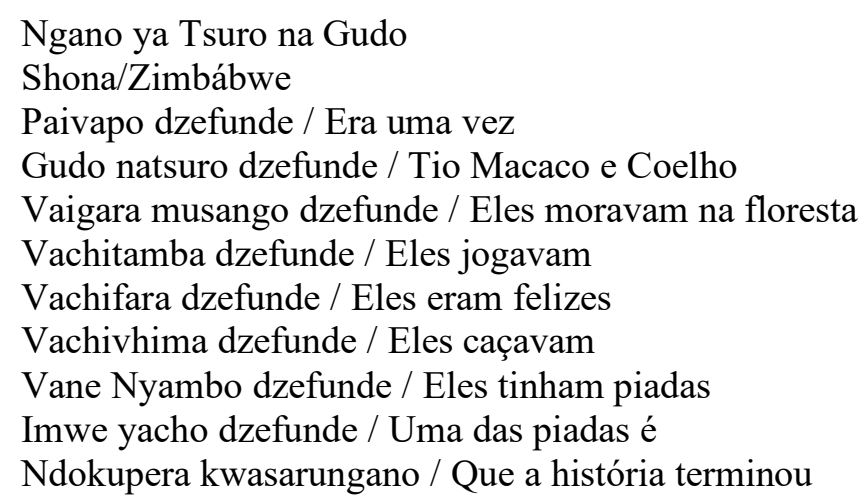


Algumas griotagens observadas por nós, nas atividades desenvolvidas por Kadidja, remetem ao movimento, à corporeidade e à circularidade. E, como observara Rosa (2013):

A estrutura mental afro-brasileira é integrativa e não excludente, humanista e não tecnicista, polivalente, visa à unidade dos elementos em sua diversidade e não a sua fragmentação, abre espaço ao inesperado e ao desconhecido que trazem novos arranjos e formas de entrosamento, caules novos desenvolvidos de raízes ancestrais (ROSA, 2013, p. 60).

Nós aprendemos e compreendemos o mundo, não somente a partir das palavras escritas ou lidas, mas também e inicialmente o aprendemos através do nosso corpo, nossas vozes, nossas expressões, vivências e experiências individuais ou coletivas.

Os saberes ancestrais e a educação das sensibilidades são mais facilmente acessados se estiverem disponíveis numa linguagem acessível ao próprio povo ao qual lhes pertence, para que seu legado seja (re)conhecido e valorizado.

A concepção circular de mundo e a renovação cíclica não linear, são inerentes à cosmovisão africana, onde o começo e o fim são um contínuo, sendo o círculo a disposição mais inclusiva possível porque nele todos os participantes de alguma maneira são contemplados e onde podemos olhar nos olhos uns dos outros, nos tocarmos, nos acariciamos, nos sentimos, enfim, interagimos.

Nas culturas tradicionais, a circularidade está presente nas rodas, giras, cirandas, canções, brincadeiras e tantas outras expressões socioemocionais (PACHECO, 2016).

Valorizar nossas origens perpassa um autorreconhecimento e o desenvolvimento de um auto-conceito positivo em relação a nossa ancestralidade pensando sempre no que nós somos e de onde viemos.

Ancestralidade é um conceito fundamental, uma coisa básica para pensar cultura africana. A ancestralidade abrange uma geração de pessoas, o território onde essas pessoas moraram, as coisas que elas construíram, que elas aprenderam, e os conhecimentos que elas adquiriram durante um espaço de tempo. É um grande aprendizado da história e da cultura, que é guardada por uma geração, mas que ela transmite para a próxima com diversos métodos dentro da sociedade. Então ancestralidade é pensar o que nós fomos, o que nós somos, e o que nós vamos ser no futuro (CUNHA Jr., 2015).

Conhecer e reconhecer a riqueza através da memória e tudo que pode acessá-la, não apenas contemplando o tempo passado, mas também o tempo presente e o porvir, auxilia-nos a desenvolver mais efetivamente e também fortalecer os laços com a nossa ancestralidade. 
Kadidja também apresenta, mesmo que de maneira bem sucinta, o conceito de "ubuntu" como, não apenas uma filosofia de vida africana de coletividade, mas também como um modo de ser, estar e resistir no mundo para que os momentos sejam de aprendizado afro-centrado e coletivo.

É possível através das griotagens descritas, evocarmos essas questões de maneira suave e livre de cobranças ou ainda poder dizer que são questões trabalhadas e aceitas pelos docentes que participam da formação docente, comprometidos e comprometidas após a formação a utilizá-las em suas aulas.

\section{CONSIDERAÇÕES FINAIS}

Nós acreditarmos que as atividades desenvolvidas pela profa. Kadidja nos possibilita pensar sobre a viabilidade de brincadeiras e canções africanas enquanto práxicas afroperspectivadas na formação docente e cotidiano escolar, embora não pretende encerrar-se nelas mesmas, até porque seria incoerente com a proposta de uma educação contra-hegemônica que, não rompa, mas dialogue com tantas práticas pedagógicas pluriversais possíveis.

Também é preciso entender que "o Brasil vive historicamente uma tensão entre os padrões estéticos reais, negros, brancos, indígenas, miscigenados e um desejo de branqueamento ou da brancura" (ROSA, 2018, p. 172) e pesquisas como essa são essenciais para essa superação.

Inicialmente nós apresentamos nesse trabalho um levantamento de produções acadêmicas que de alguma maneira tocam nas temáticas das brincadeiras e canções tradicionais e africanas, percebendo que a seara dessas pesquisas ainda carece de um maior volume de pessoas que se debrucem nas possibilidades efetivas de afrocentrar a formação docente e também a possibilidade de um currículo escolar que contemple as relações étnico-raciais, e não somente ele, mas a vida de todos e todas, negros e negras diaspóricos, e também os não negros e não negras que pouco têm contato com uma forma positivada da história e cultura afro.

Em seguida nós discorremos de forma sucinta acerca de três práticas pedagógicas afro-referenciadas e/ou contra-hegemônicas: a "Pretagogia", a "Pedagoginga" e a "Pedagogia Griô". Em comum, essas práticas são pautadas em saberes tradicionais e 
valorização da oralidade, corporeidade e memória, dentre outros aspectos inerentes à ancestralidade africana como um pensamento pluriversal e inclusivo.

Finalmente, e sem a pretensão de esgotar o tema, afinal "o novo brota sem parar" (MORIN, 2007, p. 30), apresentamos algumas atividades, dentre tantas, que a profa. Kadidja aplica em seus cursos e oficinas de formação docente, com diversas brincadeiras e canções africanas inseridas no cotidiano da formação docente e escolar e que auxiliam sobremaneira à uma pedagogia afrocentrada, que lê o ser humano biocentricamente em sua diversidade étnico-racial e intercultural analisadas à luz das pedagogias contrahegemônicas.

Ao trazermos essa reflexão sobre as brincadeiras e canções africanas ou afrocentradas, majoritariamente em línguas africanas tradicionais (indicando suas respectivas localidades ou etnias sempre que possível), percebemos que brincando e cantando, os docentes, as crianças, jovens e adultos experenciam e vivenciam polidiálogos interculturais onde docentes vislumbram a transformação de sua prática pedagógica eurocêntrica em práxica afroperspectivada não hierarquizando saberes mas transitando entre conhecimentos ora sistematizados ora de tradições ancestrais e todos e todas acabam por valorizar a legitimidade de todos os saberes ancestrais.

A cosmo-sensação e cosmovisão africanas subsidiando a práxicas afroperspectivadas enegrecem a formação docente tão branqueada pelas teorias eurocentradas e favorecem uma educação decolonial que valorize e enobrece os saberes tradicionais bem como as relações humanas numa busca da reeducação das relações étnico-raciais.

\section{REFERÊNCIAS BIBLIOGRÁFICAS}

BÂ, Amadou Hampaté. Amdoullel, o menino fula. São Paulo: Companhia das Letras / Casa das Áfricas, 2003.

BEZERRA, Carolina dos Santos. Saravá Jongueiro Velho: memória e ancestralidade no jongo de Tamandaré. Juiz de Fora: UFJF, 2012.

BROUGÈRE, Gilles. Brinquedo e cultura. São Paulo: Cortez, 2008.

CUNHA Jr. Henrique. Entrevista. Documentário Nota 10, III, Episódio 08: Ancestralidade. Canal Futura. 07 de julho de $2015 . \quad$ Disponível em: $<\underline{\text { https://www.youtube.com/watch? } v=b N F L 2 i P q n R Q>}>$. Acesso em: 02/01/2019. 
FERNANDES, Benecta Patrícia Fernandes e. Jogos e Brincadeiras Tradicionais e Eletrônicas Infantis: Significados do Brincar para crianças de uma escola pública do município de Piracicaba-. Dissertação (Mestrado em Educação Física) - Universidade Metodista de Piracicaba, São Paulo, 2015.

MACHADO, Vanda. Ilê Axé: vivências e invenção pedagógica as crianças do Opô Afonjá. Salvador: EdUFBA, 2002.

MORIN, Edgar. Introdução ao pensamento complexo. Porto Alegre: Sulina, 2007.

NASCIMENTO, Sergio Luis do; OLIVEIRA, Julvan Moreira de. A construção do legado: a negação de uma epistemologia filosófica africana. In Revista da ABPN, vol. 8, $\mathrm{n}^{\circ}$. 19. Março a Junho de 2016, pp. 177-194. Disponível em: $<$ http://abpnrevista.org.br/revista/index.php/revistaabpn1/article/view/31/28>. Acesso em: 20/11/2019.

OLIVEIRA, Julvan Moreira de. Educação e africanidades: contribuições do pensamento de Kabengele Munanga. In: 32 Reunião da ANPED - Sociedade, Cultura e Educação: novas regulações?. Rio de Janeiro: ANPED (Associação Nacional de Pós-graduação e Pesquisa em Educação), 2009, pp. 01-16. Disponível em: $<$ http://32reuniao.anped.org.br/arquivos/trabalhos/GT21-5390--Int.pdf $>$. Acesso em 11/08/2019.

PACHECO, Lílian. Pedagogia Griô: a reinvenção da Roda da Vida. Lençóis/Bahia: Ministério da Cultura: Programa Cultura Viva/Ação Griô Nacional/Ponto de Cultura Grãos de Luz e Griô, 2006. Disponível em: $\quad$ http://graosdeluzegrio.org.br/compre-nossos-produtos/livros/apedagogia-grio/>.

PETIT, Sandra Haydée. Pretagogia: Pertencimento, Corpo-Dança Afroancestral e Tradição Oral Africana na Formação de Professoras e Professores. Fortaleza: EdUECE, 2015.

PETIT, Sandra Haydée. Práticas pedagógicas para a lei n. 10.639/2003: a criação de nova abordagem de formação na perspectiva das africanidades. In OLIVEIRA, J. M. (org.) Trajeto das Africanidades em Educação. Educação em Foco, vol. 21, n. 3, pp. 657-684, setembro a dezembro de 2016. Disponível em: < http://ojs2.ufjf.emnuvens.com.br/edufoco/issue/view/847>. Acesso em: 11/08/2018.

ROSA, Allan da. Imaginário, corpo e caneta: matriz afro-brasileira em educação de jovens e adultos. Dissertação, 2009. Disponível em: $<$ http://www.teses.usp.br/teses/disponiveis/48/48134/tde-23032010-144503/pt-br.php>.

ROSA, Allan da. Pedagoginga: autonomia e mocambagem. São Paulo: Pólen, 2019.

SILVA, Jussara Alves da. Karingana wa karingana: brincadeiras e canções africanas. Dissertação de Mestrado - Programa de Pós-graduação em Educação da Universidade Federal de Juiz de Fora. Juiz de Fora, 2019. Disponível em:

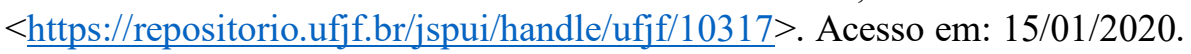

SILVA, Maurício. Resenha. Revista X, vol. 12, n. 1, pp. 184-186, 2017. Disponível em $<$ https://revistas.ufpr.br/revistax/article/view/50113/33107>. Acesso em 28/05/2018.

SOUZA, Lidiane Cristina Loiola. Canções, ritmos, histórias... brincando, cantando e dançando a África. Revista África e Africanidades, n. 23, abril de 2017. Disponível em: $<$ http://www.africaeafricanidades.com.br/edicao23.html $>$. Acesso em: 08/01/2019. 
TRAVERZIM, Monique. Brincadeiras Tradicionais da Cultura da Infância na formação musical do pedagogo. Dissertação (Mestrado em Música) - Universidade Estadual Paulista. São Paulo, 2015.

Recebido 30/11/2019

Aprovado em: $30 / 01 / 2020$ 